\title{
Key Genes in Lung Cancer Translational Research: A Meta-Analysis
}

\author{
J.T. Amelung ${ }^{a} \quad$ R. Bührens ${ }^{a} \quad$ M. Beshay ${ }^{b, c} \quad$ M.A. Reymond ${ }^{b, c}$ \\ ${ }^{a}$ Westfalian Wilhelms University Münster, Münster, ${ }^{b}$ Evangelic Hospital Bielefeld, Bielefeld, \\ 'Otto-von-Guericke University Magdeburg, Magdeburg, Germany
}

\section{Key Words}

cDNA array • Lung cancer • Meta-analysis • Non-small cell lung cancer $\cdot$ Small cell lung cancer $\cdot$ Translational research

\begin{abstract}
In lung cancer, integrating translational data from various histologies obtained in different patients under different conditions can increase their robustness. This is a meta-analysis of cDNA array data obtained in 688 tumor patients (541 non-small cell lung cancer, 33 small cell lung cancer and 114 others) and 205 controls. 1,206 genes were found to be dysregulated in one of the 12 transcriptomics studies available. 748 results (62\%) were obtained only once and might be questioned. $38 \%$ of observations could be reproduced twice or more. 346 genes were reported twice, 80 three times, 27 four and 5 five times. A common set of genes dysregulated in lung cancer was obtained, including BPA1, DUSP6, ASCL1, RNAS1 and S100P. p63 and CK 5/6 p63 are useful for differentiating adenocarcinoma and small cell lung cancer from squamous cell carcinoma. TFF-3 and MUC1 are over-expressed in adenocarcinoma. INSM1, SGNE1 and H2AFZ are typical for small cell lung cancer. Using a meta-analysis approach, it was possible to detect a robust set of genes differentially expressed in lung cancer and to determine a limited number of key genes linked to subtypes in lung cancer molecular pathology.

Copyright $\odot 2010$ S. Karger AG, Basel
\end{abstract}

\section{Introduction}

In 2006, lung cancer was the most common cause of death from cancer in Europe, with an estimated 334,800 mortalities (19.7\% of the total attributable to cancer) [1]. Since no screening method is available to date, most lung cancers are of considerable size when detected, and about $60 \%$ are incurable as a result of local invasion or distant metastasis at time of diagnosis. It is estimated that only $10 \%$ of patients survive 5 years after diagnosis.

Beside anti-smoking campaigns aimed at reducing lung cancer incidence, these unfavorable figures underscore the urgent need for early diagnostic tools and better drug therapy. Against this framework, the appearance about 10 years ago of high-throughput, large-scale gene expression research tools, in particular cDNA arrays, has generated high expectations in translational lung cancer research.

These techniques have been used with great success for molecular profiling in oncology. However, with growing availability of data, it has become apparent that results obtained are highly variable. Translational studies in human patients are usually characterized by small size, various sample preparation techniques and the use of varying technologies. Not only it has become difficult for the individual researcher to get an overview of the hundreds of publications and terabytes of data available, but these results are also in part contradictory.

\section{KARGER}

Fax +4161306 1234

E-Mail karger@karger.ch

www.karger.com (c) 2010 S. Karger AG, Basel

$1015-2008 / 10 / 0772-0053 \$ 26.00 / 0$

Accessible online at:

www.karger.com/pat
Prof. Marc A. Reymond, MD, MBA

Department of General, Gastrointestinal and Thoracic Surgery

Evangelic Hospital Bielefeld, Schildescher Strasse 99

DE-33611 Bielefeld (Germany)

Tel. +49521 772 77401, Fax +49521 772 77402, E-Mail marc.reymond@evkb.de 
Several studies have shown the applicability and reproducibility of the microscopic classification of lung cancer derived by the scheme originally adopted by the WHO committee [2]. These categories are small cell lung cancer (SCLC) and non-small cell lung cancer (NSCLC), which mainly includes squamous cell carcinoma and adenocarcinoma. However, part of the difficulty in sharply separating lung carcinomas into this classification stems from the fact that up to two thirds of them show a combination of patterns [3]. Moreover, the problem of profiling these subtypes is worsened by the limited availability of clinical samples, in particular for SCLC.

Thus, to transfer translational research data from the bench to the bedside, there is an obvious need to integrate data from various histologies obtained in different patients under different conditions, in order to increase the robustness of these data. Indeed, to detect universal biomarkers, integrated translational research analysis based on large patient groups is required [4]. As in clinical medicine, meta-analysis methodology can improve the level of evidence and meet significance.

The aim of the present meta-analysis was to detect a robust set of genes differentially expressed in lung cancer and, if possible, to find out a limited number of key genes linked to subtypes in lung cancer molecular pathology.

\section{Materials and Methods}

\section{Principles of Analysis}

According to the above observations, we assumed that, for confirming gene expression results obtained in independent studies on lung cancer, it would be useful to compare and contrast the results obtained in these individual studies. For example, if a single author claims that the over-expression of secretory granule neuroendocrine protein 1 is a specific feature of SCLC, then this finding has to be confirmed in another independent study on SCLC. If this over-expression is not confirmed, then the hypothesis is rejected. If, however, it is regularly confirmed in slightly different but related contexts, then it can be assumed that this over-expression is a robust observation specific to SCLC.

In this respect, we do not consider it useful to compute the individual level of over- or under-expression of a given gene in a particular setting. There are several reasons to justify this choice:

- cDNA arrays experiments are necessitating a pre-amplification of genetic material so that the technology is only semiquantitative;

- there is no internal standard between different experiments;

- phenotypically different types of cancers are compared;

- genotypic backgrounds vary among individuals;

- microscopic diagnosis has not been confirmed by a reference pathologist;
- no sample preparation (e.g. enrichment of epithelial cells) was performed, so a heterogeneous proportion of cancer cells in the specimen is to be expected;

- different array generations with different sets of genes have been used;

- chips were purchased from different manufacturers.

Moreover, such attempts to determine the median or mean level of gene expression throughout different experiments is not necessary for detecting potential genes of interest.

We believe that the simplest and the most robust method of assessment of differential gene expression is to classify the results into 3 categories:

- statistically significant over-expression;

- statistically significant under-expression;

- no differential expression but expression observed.

The third category is useful for discriminating between missing and identical results.

On the basis of this simple classification, it is possible to rank the genes between different studies, to detect the common set of genes in a given pathology, and also to contrast results between different histology. Only raw data are used, and only descriptive statistics provided, so that possible bias induced by statistical data manipulation can be excluded. In a previous publication, we have shown that the results obtained using this straight strategy are very close to sophisticated statistical methods [5] and allow us to discriminate the genes of interest.

This conservative, non-quantitative approach is supported by recent methodological data reporting that a number of genes show a small fold-change in one cDNA platform and a large foldchange in another platform, even though the correlations between platforms are high. Thirty percent of gene expressions of the samples showed inconsistent patterns across different platforms. A non-overlapping gene can be truly differentially expressed with a stringent cut, and an overlapping gene can be nondifferentially expressed with non-stringent cutoff. There is no criterion to determine a cutoff so that the percent of overlapping genes is optimized [6].

\section{Selection of the Publications}

Rather than applying sophisticated statistical methods or simulation models, we spent much more time in selecting appropriate studies. It was a priority to set up a relatively large collection of studies that would allow us to draw robust conclusions. Using the key words '(cDNA array or oligonucleotide) AND lung cancer', 2,363 studies were downloaded from PubMed, representing terabytes of gene expression data. We applied the following selection criteria:

- only studies in human patients;

- only analysis of tissue samples;

- no studies on cell lines;

- comparison between tumor and non-tumor tissue;

- no prognostic studies comparing different outcomes.

After applying the selection criteria above, 12 studies remained available for further study. Eight of these studies used cDNA arrays, and 4 used oligonucleotide arrays. These studies are summarized in table 1. Altogether, 688 tumor patients and 205 controls were analyzed. The following histologies were considered:

- 541 NSCLC (361 adenocarcinoma, 141 squamous cell carcinoma and 39 not further specified);

- 33 SCLC; 
Table 1. Summary of the studies used in this meta-analysis

\begin{tabular}{|c|c|c|c|c|c|}
\hline Author [ref] & Year & $\begin{array}{l}\text { Sample } \\
\text { origin }\end{array}$ & Methods & $\begin{array}{l}\text { Tumor } \\
\text { patients }\end{array}$ & Reference samples \\
\hline Spira et al. [37] & 2007 & tissue & oligonucleotide microarray & 60 & unknown \\
\hline Chen et al. [38] & 2007 & tissue & microarray + RT-PCR & 125 & 60 \\
\hline Woenckhaus et al. [39] & 2006 & tissue & oligonucleotide microarray & 27 & 8 \\
\hline Taniwaki et al. [40] & 2006 & tissue & cDNA microarray & 15 & 15 \\
\hline McDoniels-Silvers et al. [43] & 2002 & tissue & competitive cDNA library screening & 14 & 14 \\
\hline Beer et al. [44] & 2002 & tissue & oligonucleotide microarray & 86 & 10 \\
\hline Amatschek et al. [45] & 2004 & tissue & cDNA subtraction + cDNA microarray & 22 & 22 \\
\hline Wikman et al. [46] & 2004 & tissue & cDNA microarray & 37 & 4 \\
\hline Heighway et al. [47] & 2002 & tissue & cDNA microarray & 39 & 39 \\
\hline Nakamura et al. [48] & 2003 & tissue & cDNA microarray & 10 & 10 \\
\hline
\end{tabular}

- 54 various histology (carcinoids, adenosquamous cancer, large cell lung cancer, neuroendocrine tumors);

- 60 lung cancers without further characterization.

For constructing the database, we considered cDNA array experiments as a semi quantitative and not quantitative analysis. For analysis, results were ranked according to the number of citations in the different studies. The possibility of adding over- or under-expression scores (see above) was rejected because of the risk of mutual exclusion in case of contradictory results between studies or between different histology.

\section{Results}

1,206 genes have been reported to be dysregulated (upand/or down-regulated) in human lung cancer, representing about $5 \%$ of the $20,000-25,000$ human genes according to the Human Genome Project information [7].

The vast majority of the 1,206 dysregulated genes in human lung cancer were found to be differentially expressed in only one of the 12 transcriptomics studies available. Of course, the validity of these 748 results obtained in only a single observation ( $62 \%$ of total data) might be questioned.

The other findings, representing $38 \%$ of observations, could be reproduced 2 or more times. This does not necessarily mean that the results have been obtained by 2 independent authors, since double observations might have been obtained by the same author in 2 different histological subtypes. 346 genes were reported twice, 80 three times, 27 four times and 5 five times. No gene was reported to be differentially expressed in 6 observations or more.

Meta-Analysis of Key Genes in Lung

Cancer Translational Research
On the basis of this simple classification, it was possible to rank the genes between different studies, to detect the common set of genes in a given pathology, and also to contrast results between different histology.

\section{Common Set of Genes in Lung Cancer}

A core set of common genes regularly reported to be dysregulated in all human lung cancer histologies could be determined. These genes are summarized in table 2 . Dystonin belongs to the plakin family of cytoskeleton linker proteins. These proteins are unique in their abilities to form bridges between different cytoskeleton elements through specialized modular domains, in particular actin and microtubule binding domains [8]. Moreover, patients suffering chronic lymphocytic leukemia develop an autoimmune vesiculobullous disease associated with the underlying malignancy, the socalled paraneoplastic pemphigus, and develop characteristic IgG auto antibodies against dystonin (reviewed in [9]). Dual specificity protein phosphatase 6 (DUSP6) is a strong tumor suppressor gene candidate in cancer and an inhibitor of phospho-ERK1/2. DUSP6 is up-regulated in a majority of dysplastic cells in pancreatic ducts but down-regulated in invasive carcinoma cells [10]. In human bronchial epithelium, mutant EGFRs were associated with increased expression of DUSP6 [11]. The basic helix-loop-helix protein, achaete-scute complex-like 1/achaete-scute homologue 1 (ASH1), is expressed in normal fetal pulmonary neuroendocrine cells and lung cancers with neuroendocrine elements and is suggested to be involved in lung carcinogenesis. Recent experimental evidence has suggested that ASH1

Pathobiology 2010;77:53-63 
Table 2. Genes reported 4 or more times to be deregulated in lung cancer, classified by subtype

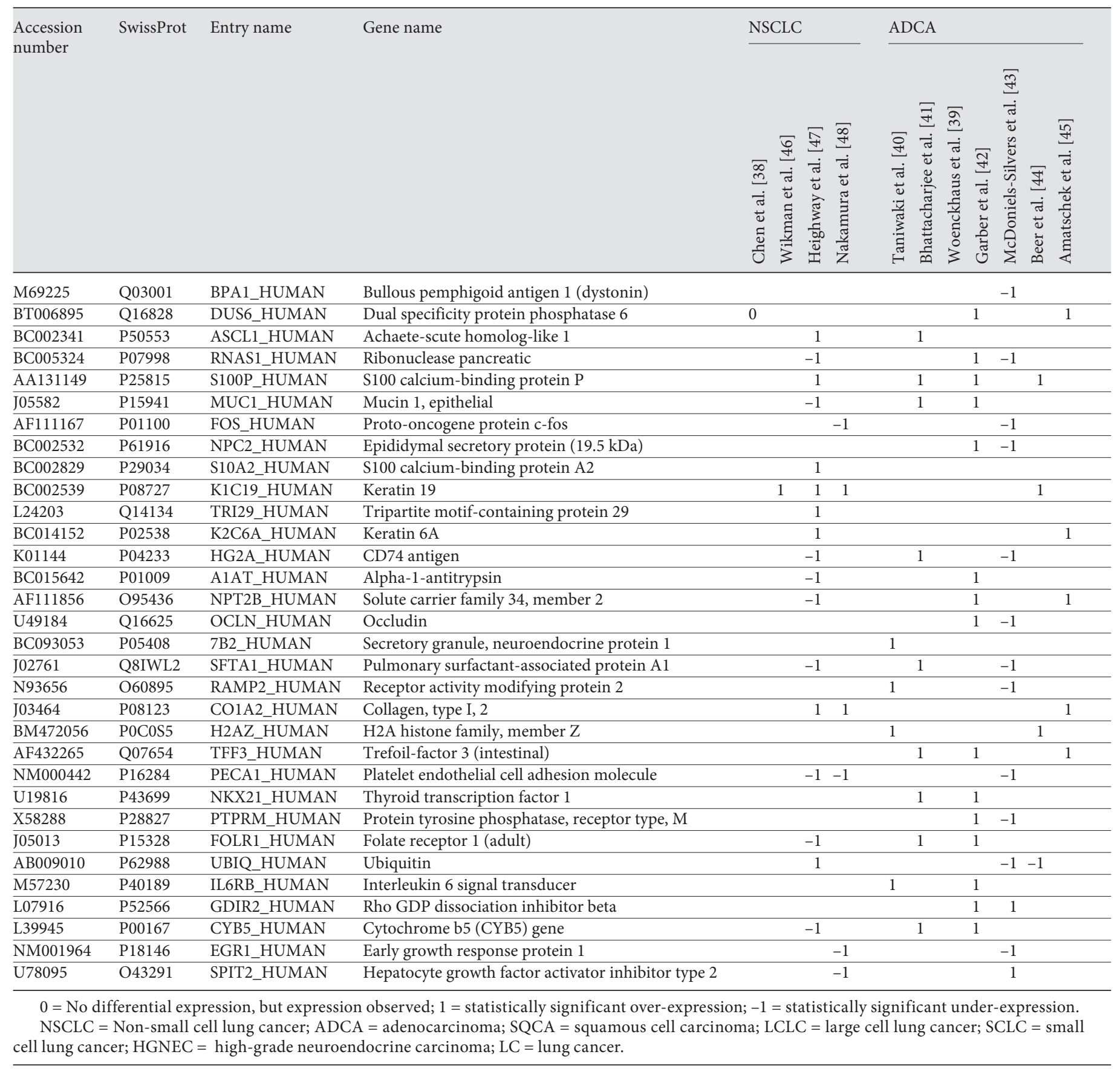

gene is a specific therapeutic target for lung cancers with neuroendocrine features [12]. Pancreatic ribonuclease (RNase A) is down-regulated in lung cancer. Ranpirnase, a cytotoxic ribonuclease from the frog Rana pipiens, has been developed as a novel chemotherapeutic agent. In combination with doxorubicin, it is used in clinical trials for the treatment of unresectable malignant mesothelioma and other cancers. The putative mechanism for ranpirnase-mediated cytotoxicity involves binding to anionic components of the extracellular membrane, cytosolic internalization and degradation of transfer RNA leading to apoptosis [13]. S100 cal- 


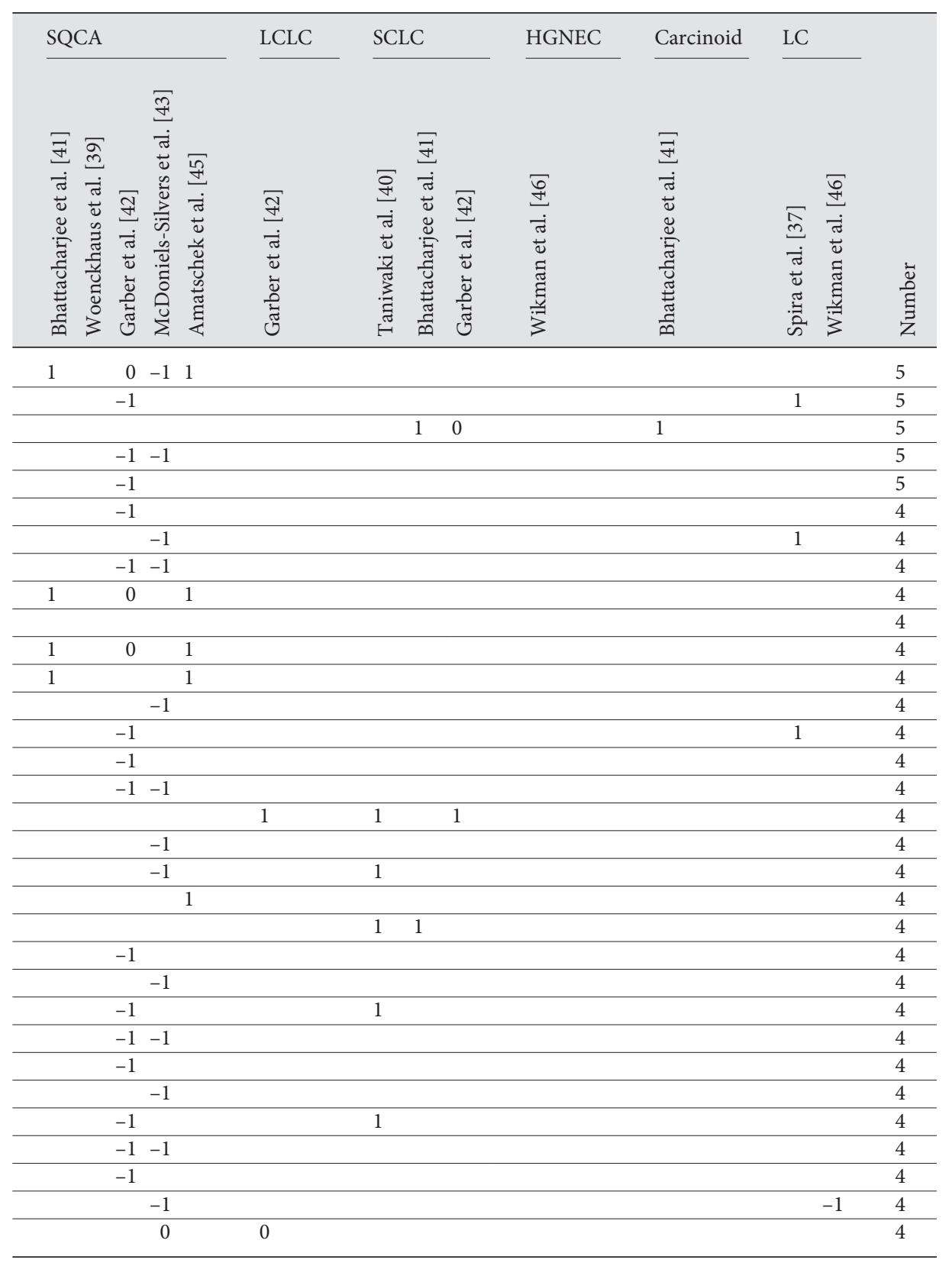

cium-binding protein $\mathrm{P}(\mathrm{S} 100 \mathrm{P})$ is a member of the $\mathrm{S} 100$ family of calcium-binding proteins. Up-regulation of $\mathrm{S} 100 \mathrm{P}$ is an early molecular event in the development of pancreatic cancer and it is expressed at high levels in both precursor lesions and invasive cancer. Over-expression of S100P changes the expression levels of sev- eral cytokeratins and up-regulates cathepsin $\mathrm{D}$, which is involved in cellular invasion [14].

\section{Differences between Histologies}

Comparison of the ordered gene lists generated from gene expression experiments in various lung cancer his- 
Table 3. Most cited up-regulated (1), down-regulated (-1), or mentioned (0) genes in human squamous cell carcinoma, sorted by expression level

\begin{tabular}{|c|c|c|c|c|c|c|c|c|c|c|}
\hline $\begin{array}{l}\text { Accession } \\
\text { number }\end{array}$ & SwissProt & Entry name & Gene name & 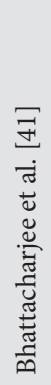 & 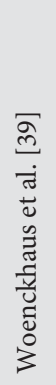 & 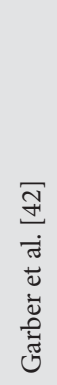 & 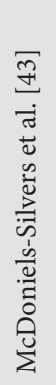 & 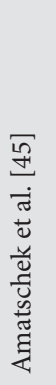 & $\begin{array}{l}\dot{\bar{\Xi}} \\
\text { है } \\
\text { ż }\end{array}$ & 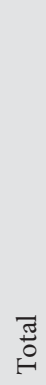 \\
\hline M21389 & P13647 & K2C5_HUMAN & Keratin 5 & 1 & & 1 & & 1 & 3 & 3 \\
\hline BT006794 & O60218 & AK1BA_HUMAN & Aldo-keto reductase family 1, member B10, B11 & & 1 & & & 1 & 2 & 2 \\
\hline L24203 & Q14134 & TRI29_HUMAN & Tripartite motif-containing protein 29 & 1 & & 0 & & 1 & 3 & 2 \\
\hline X62571 & Q04695 & K1C17_HUMAN & Keratin 17 & 1 & & 1 & & & 2 & 2 \\
\hline BC002829 & P29034 & S10A2_HUMAN & S100 calcium-binding protein A2 & 1 & & 0 & & 1 & 3 & 2 \\
\hline M69225 & Q03001 & BPA1_HUMAN & Bullous pemphigoid antigen 1 (dystonin) & 1 & & 0 & -1 & 1 & 4 & 1 \\
\hline L07769 & $\mathrm{P} 47929$ & LEG7_HUMAN & Galectin-7 & 1 & & 0 & & & 2 & 1 \\
\hline L02870 & Q02388 & CO7A1_HUMAN & Collagen alpha-1(VII) & 1 & & 0 & & & 2 & 1 \\
\hline BC002532 & P61916 & NPC2_HUMAN & Epididymal secretory protein $(19.5 \mathrm{kDa})$ & & & -1 & -1 & & 2 & -2 \\
\hline BC005324 & P07998 & RNAS1_HUMAN & Ribonuclease, RNase A family, 1 (pancreatic) & & & -1 & -1 & & 2 & -2 \\
\hline L07916 & P52566 & GDIR2_HUMAN & Rho GDP dissociation inhibitor (GDI) beta & & & -1 & -1 & & 2 & -2 \\
\hline U49184 & Q16625 & OCLN_HUMAN & Occludin & & & -1 & -1 & & 2 & -2 \\
\hline $\mathrm{X} 58288$ & P28827 & PTPRM_HUMAN & Protein tyrosine phosphatase, receptor type, $\mathrm{M}$ & & & -1 & -1 & & 2 & -2 \\
\hline AF069668 & P35754 & GLRX1_HUMAN & Glutaredoxin & & -1 & -1 & & & 2 & -2 \\
\hline
\end{tabular}

Number $=$ Frequency of citation; total $=$ expression level.

tological types allowed us to not only detect a common core set of genes (see above), but also to determine genes typically dysregulated in a single histological type, suggesting involvement in histology-specific biological processes.

Genes typically deregulated in squamous cell lung cancer are summarized in table 3 . Tumor protein 63 (p63), cytokeratins 5 and 6 (CK 5/6), p63 and CK 5/6 seem to be useful for differentiating adenocarcinoma and SCLC from squamous cell carcinoma with 100\% specificity and $82 \%$ sensitivity, and $89 \%$ specificity and $79 \%$ sensitivity, respectively [15]. The expression of tight junction proteins, including occludin, differs between human lung squamous cell carcinomas and adenocarcinomas: in squamous cell carcinomas, the mRNA level of occludin is down-regulated [16], or disappears in squamous cell carcinoma, large cell carcinoma, small cell carcinoma, and large cell neuroendocrine carcinoma [17]. Erlotinib, an epidermal growth factor receptor tyrosine kinase inhibitor, has clinical activity in advanced lung cancer, but mechanism of acquired resistance is unclear. We recommend that the biomedical significance in squamous cell lung cancer of other molecules such as dystonin or tripartite motif-containing protein 29 should be the object of further focused research.

Specific patterns of gene expression have also been reproduced in lung adenocarcinoma (table 4). Trefoil-factor 3, intestinal (TFF-3) is known to play key roles in mucosal protection through mucous-barrier formation, and also in mucosal repair through promotion of restitution after injury [18] and - in the present meta-analysis - has been found to be over-expressed in 3 studies on lung adenocarcinoma, but down-regulated in squamous cell cancer. TFFs are associated with mucin-secreting epithelial cells [19], and it is no surprise that mucin-1 (epithelial) has been found to be up-regulated in lung adenocarcinoma. The role of mucin in the biological underpinning [20] and in vaccination strategies [21] in lung adenocarcinoma has been extensively studied. Over-expression of fructose-bisphosphate aldolase A in lung can- 
Table 4. Most cited up-regulated (1), down-regulated (-1) or mentioned (0) genes in human adenocarcinoma, sorted by expression level

\begin{tabular}{|c|c|c|c|c|c|c|c|c|c|c|c|c|}
\hline $\begin{array}{l}\text { Accession } \\
\text { number }\end{array}$ & SwissProt & Entry name & Gene name & 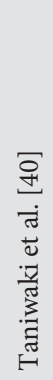 & 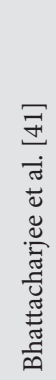 & 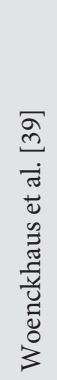 & 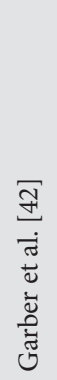 & 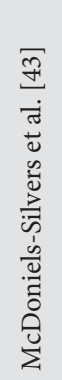 & 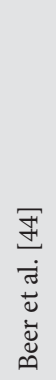 & 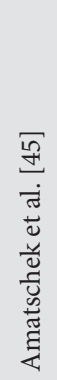 & 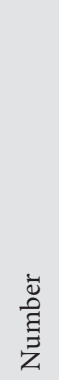 & సేّ \\
\hline AA131149 & P25815 & S100P_HUMAN & S100 calcium-binding protein $\mathrm{P}$ & & 1 & & 1 & & 1 & & 3 & 3 \\
\hline$\overline{\mathrm{AF}} 432265$ & Q07654 & TFF3_HUMAN & Trefoil-factor 3 (intestinal) & & 1 & & 1 & & & 1 & 3 & 3 \\
\hline $\bar{J} 05582$ & P15941 & MUC1_HUMAN & Mucin-1, epithelial & & 1 & & 1 & & & & 2 & 2 \\
\hline M11767 & P04626 & ERBB2_HUMAN & Tyrosine kinase-type cell surface receptor HER2 & & & & 1 & & 1 & & 2 & 2 \\
\hline$\overline{\mathrm{AF} 111856}$ & O95436 & NPT2B_HUMAN & Solute carrier family 34 , member 2 & & & & 1 & & & 1 & 2 & 2 \\
\hline$\overline{\mathrm{U} 46692}$ & P04080 & CYTB_HUMAN & Cystatin B (stefin B) & & & & & & 1 & 1 & 2 & 2 \\
\hline X05236 & P04075 & ALDOA_HUMAN & Fructose-bisphosphate aldolase A & & & & & 1 & 1 & & 2 & 2 \\
\hline K03195 & P11166 & GTR1_HUMAN & Solute carrier family 2, member 1 & & & & & & 1 & 1 & 2 & 2 \\
\hline M57230 & P40189 & IL6RB_HUMAN & Interleukin 6 signal transducer & 1 & & & 1 & & & & 2 & 2 \\
\hline U19816 & P43699 & NKX21_HUMAN & Thyroid transcription factor 1 & & 1 & & 1 & & & & 2 & 2 \\
\hline U21108 & Q13115 & DUS4_HUMAN & Dual specificity phosphatase 4 & & 1 & & 1 & & & & 2 & 2 \\
\hline AB034951 & P11142 & HSP7C_HUMAN & Heat shock cognate $71-\mathrm{kDa}$ protein & & & & 1 & & 1 & & 2 & 2 \\
\hline$\overline{A Y 762101}$ & P05783 & K1C18_HUMAN & Keratin 18 & & & & 1 & & 1 & & 2 & 2 \\
\hline $\mathrm{X} 17094$ & P09958 & FURIN_HUMAN & Furin (paired basic amino acid cleaving enzyme) & & & & 1 & & 1 & & 2 & 2 \\
\hline$\overline{\mathrm{D} 29992}$ & P48307 & TFPI2_HUMAN & Tissue factor pathway inhibitor 2 & & & & 1 & & & 1 & 2 & 2 \\
\hline$\overline{Z 93930}$ & P17861 & XBP1_HUMAN & X-box binding protein 1 & & 1 & & 1 & & & & 2 & 2 \\
\hline $\bar{J} 02761$ & Q8IWL2 & SFTA1_HUMAN & Pulmonary surfactant-associated protein A1 & & 1 & & & -1 & & & 2 & 0 \\
\hline N93656 & O60895 & RAMP2_HUMAN & Receptor (calcitonin) activity modifying protein 2 & 1 & & & & -1 & & & 2 & 0 \\
\hline L06623 & P24530 & EDNRB_HUMAN & Endothelin receptor type B & & & -1 & 1 & & & & 2 & 0 \\
\hline$\overline{\mathrm{AB} 029025}$ & Q9UPQ0 & LIMC1_HUMAN & LIM and calponin homology domains-containing protein 1 & & & -1 & 1 & & & & 2 & 0 \\
\hline$\overline{\text { BT007090 }}$ & P62328 & TYB4_HUMAN & Thymosin beta- 4 & & & & & 0 & -1 & & 2 & -1 \\
\hline $\mathrm{AB} 009010$ & P62988 & UBIQ_HUMAN & Ubiquitin & & & & & -1 & -1 & & 2 & -2 \\
\hline
\end{tabular}

Number $=$ Frequency of citation; total $=$ expression level.

cer has been known for two decades [22], and the presence of the enzyme in the blood of bronchial cancer patients even longer [23]. Lung adenocarcinomas showed higher pulmonary surfactant-associated proteins A1/ surfactant-apoproteins A2 ratios than the tumor-free tissues and squamous cell cancer [24]. Also here, the bio- logical significance of other genes typical of pulmonary adenocarcinoma deserves more attention.

Some genes of particular interest show differential behavior in lung adenocarcinoma and in squamous cell lung cancer. For example, Rho GDP dissociation inhibitor beta is up-regulated in lung adenocarcinoma ( 2 stud- 
Table 5. Genes differentially expressed in NSCLC and SCLC

\begin{tabular}{|c|c|c|c|c|c|c|c|c|c|c|c|c|c|}
\hline \multirow{2}{*}{$\begin{array}{l}\text { Accession } \\
\text { number }\end{array}$} & \multirow[t]{2}{*}{ SwissProt } & \multirow[t]{2}{*}{ Entry name } & \multirow[t]{2}{*}{ Gene name } & \multicolumn{4}{|c|}{ ADCA } & \multicolumn{2}{|c|}{ SQCA } & \multicolumn{3}{|l|}{ SCLC } & \multirow[b]{2}{*}{ సేّే } \\
\hline & & & & 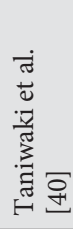 & 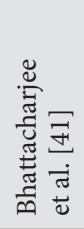 & 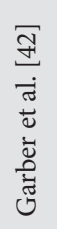 & 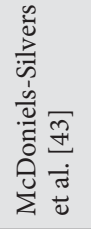 & 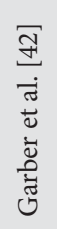 & 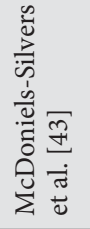 & 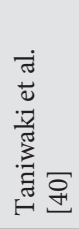 & 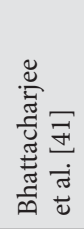 & 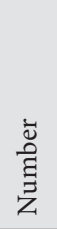 & \\
\hline U19816 & P43699 & NKX21_HUMAN & Thyroid transcription factor 1 & & 1 & 1 & & -1 & & 1 & & 4 & 2 \\
\hline$\overline{A F 363368}$ & Q8NFZ8 & CADM4_HUMAN & $\begin{array}{l}\text { Immunoglobulin superfamily, member } 4 \\
\text { (cell adhesion molecule 4) }\end{array}$ & & & 1 & & -1 & & 1 & & 3 & 1 \\
\hline N93656 & O60895 & RAMP2_HUMAN & $\begin{array}{l}\text { Receptor (calcitonin) activity modifying } \\
\text { protein } 2\end{array}$ & 1 & & & -1 & & -1 & 1 & & 4 & 0 \\
\hline$\overline{\mathrm{X} 02308}$ & P04818 & TYSY_HUMAN & Thymidylate synthase & & & & 0 & & -1 & & 1 & 3 & 0 \\
\hline
\end{tabular}

ies) and down-regulated in squamous cell cancer (2 studies). Rho family GTPases play critical roles in maintaining the apical junctions of epithelial cells through reorganization of the actin cytoskeleton, and thus in a number of processes related to metastasis, and Rho GDP dissociation, inhibitors are regulating Rho family proteins [25].

SCLC accounts for $20-25 \%$ of all bronchogenic carcinoma and is associated with the poorest 5 -year survival of all histological types. SCLC differs from NSCLC in its etiologic, pathologic, biologic and clinical features, so differences in molecular pathology are expected. Ultrastructurally, SCLC displays a number of neuroendocrine features, including dense core vesicles or neurosecretory granules. In the present meta-analysis, a limited set of genes are typically over-expressed in SCLC, namely insulinoma-associated protein 1, H2A histone family member $\mathrm{Z}$ and secretory granule neuroendocrine protein 1 . The insulinoma-associated 1 (INSM1) gene is expressed during early embryonal development and in neuroendocrine tumors. The INSM1 promoter region shows very high levels of expression in most of the SCLC cell lines and expression is absent in cell lines of non-neuroendocrine origin so that it is considered a potential novel tool for transcriptionally targeted gene therapy for neuroendocrine tumors [26]. Secretory granule neuroendocrine protein 1 is a sensitive biochemical marker of neuroendocrine bronchial tumors in the human patient [27]. The role of $\mathrm{H} 2 \mathrm{~A}$ histone family member $\mathrm{Z}$ in lung cancer has been so far not been further characterized and deserves further research.
Of particular interest are genes differentially expressed in NSCLC and in SCLC. These genes are summarized in table 5. Thymidylate synthase (TS) is important for maintenance of the intracellular thymidine pool, which is crucial for DNA synthesis and repair. By means of both quantification by real-time PCR and immunohistochemistry, a higher TS expression in pulmonary SCLC and large cell neuroendocrine cancers compared with typical and atypical carcinoids was observed [28]. Intratumoral TS expression has been shown to be prognostic of outcome in stage I NSCLC [29]. TS is the main target of antifolate drugs, in particular of pemetrexed, a novel agent for the treatment of NSCLC, which is also currently investigated as a second-line therapy for SCLC [30]. Pemetrexed is rapidly converted to active polyglutamate derivatives in cells to achieve prolonged and potent inhibition of TS. Cyclooxygenase-2, activators of transcription 3 and IL- 6 are elevated in NSCLC, affect numerous cellular pathways and may act in concert by cyclooxygenase2-dependent activation of signal transducer and activator of transcription 3 by IL- 6 [31]. Thyroid transcription factor-1 (TTF-1) immunostains are useful for diagnosing poorly differentiated squamous cell carcinoma from SCLC [32]. Receptor activity-modifying protein 2 mediates in a dose-dependent manner the promotion of tumor angiogenesis by adrenomedullin, in particular endothelial cell migration and invasion [33]. Adhesion enables and promotes cancer-defining biological processes like growth, survival, migration, extravasation, homing and metastasis. Furthermore, cell adhesion mediates drug resistance in SCLC and NSCLC [34]. All 5 classes of 
cell adhesion molecules - integrins, cadherins, immunoglobulin-like cell adhesion molecules, selectins and CD44s - are characteristically dysregulated in human cancer. Cell adhesion molecule 4 is up-regulated in lung adenocarcinoma and SCLC but not in squamous cell cancer.

\section{Discussion}

Translational research in oncology is characterized by highly parallel array studies modeling the behavior of thousands of genes simultaneously. Due to the difficulty of accessing high-quality clinical samples, these studies are usually performed in a limited number of patients and controls. In the studies selected for the present metaanalysis, the mean number of tumor samples was 57 cancer patients versus 17 controls. So far, the number of studies available is also limited, with a total of 12 publications allowing comparison according to pre-determined inclusion and exclusion criteria.

In translational research in lung cancer, most exploratory studies have investigated differential expression between 2 different biological conditions in an independent, de novo approach. Hundreds of thousands of individual data were generated and these data were then mined to discover potential biomarkers. Of course, the level of confidence of these results can only be limited, due to heterogeneous groups of patients, no routine sample enrichment such as laser-capture microdissection or bead-based techniques, technical requirements such as pre-amplification of genetic material, and statistical considerations (number of patients, number of trials, size sample and power). There was no confirmatory study aimed at reproducing results in a second group of patients.

In lung cancer, the first meta-analyses of gene expression are now emerging and 2 published studies might be the first steps in the right direction. However, both studies available were designed using a bioinformatics approach rather than from the biological point of view [4, 35]. In the study of Fishel et al. [35], to obtain a homogeneous dataset only adenocarcinomas were included, so that only 3 data collections involving 266 lung cancer samples and 32 controls could be merged. In the second available meta-analysis [4], 186 lung cancer samples and 17 controls were compared with other cancers (breast, prostate, etc.), but no differentiation between lung cancer histologies was possible.

Altogether, using stringent inclusion and exclusion criteria, translational research results from 12 studies ob- tained in 688 tumor patients and 205 controls were merged in the present meta-analysis, resulting in the largest collection of gene expression data available to date in lung cancer. Moreover, this dataset allows contrasting results obtained in different lung cancer histologies.

The main result obtained is a core set of common genes that are dysregulated in lung cancer when compared with 'normal' tissue. These genes belong to various functional categories such as cytoskeleton, cell signaling, cell cycle, growth factors, receptors, cellular metabolism, transcription and translation. Of course, the biological significance of these results can be questioned, since many differences might not be cancer-specific. To enhance the interpretability of these findings, the metaanalysis should be extended to other organs and diseases to ensure their specificity. However, substantial publications (above) suggest that these similarity-driving genes and their products are significant in carcinogenesis, diagnosis, prognosis or even therapy, so that the proof of concept for the power of the meta-analytic approach is given. Many of the proteins/genes identified were already known and used in immunohistochemical stains, such as surfactant-related proteins, or S100-protein related factors. Other proteins (neuroendocrine secretory granule protein1, Achaete-scute homolog-like1) clearly relating to neuroendocrine differentiation have also been found in NSCLC, raising again the question of a correct tumor diagnosis. MUC genes have been previously investigated at the protein level, so the finding of MUC1 is not a surprise. Other molecules such as CK 5/6, p63, TTF1, surfactant apoproteins and precursors have been used quite a long time for differential diagnosis in pulmonary pathology.

The second important result is the determination of molecular differences between various cancer types, which was directly given by the negative picture of the determination of the similarities among gene lists. Differences were particularly evident between NSCLC and SCLC (such as insulinoma-associated 1 gene or secretory granule neuroendocrine protein 1; see above), between adenocarcinoma and squamous cell cancer (such as trefoil-factor 3 or mucin-1) and some hits concern molecules routinely applied in pathology laboratories for immunostaining of lung cancer, such as TTF-1 (above). In fact TTF-1 is not only useful to separate poorly differentiated squamous cell carcinoma from SCLC, but mainly squamous cell carcinoma from adenocarcinoma. However, the lists of potential biomarkers are rather long, and further focused research on possible clinical applications is already ongoing. 
The third finding is to quantify the variability between results. Because of the probability of random differences and false positive results, it is unsurprising that the evidence resulting from this large amount of data is rather weak, with a high level of variability between studies (only $32 \%$ of results were reproduced in at least 2 studies out of 12). Of course, if this statement is true for all studies together, then it will certainly apply to a single study taken individually. This discrepancy of results can be explained by several methodological problems highlighted in this meta-analysis. The first drawback is related to missing controls and absence of tissue verification by an experienced pathologist. In several studies (see table 1, numbers $1,4-6,9,11$ and 12) no pathological control is mentioned, suggesting that diagnosis was not confirmed by a pathological reviewer or co-author. Moreover, the authors having performed tissue selection were neither trained nor familiar with pathological entities. Therefore, the tumor sample was arbitrarily selected from a fresh tissue sample or formalin-fixed paraffinembedded tissue block handed over to the investigators. A further problem of cDNA array studies is that over-expression of a particular mRNA does not automatically mean that the corresponding protein is over-expressed too, or that the downstream signaling cascade is dysreg- ulated. Post-translational modification might be even more important than mRNAS expression by itself: miRNA might inactivate any over-expressed mRNA, splicing might elicit even completely opposite functional activities. Protein phosphorylation at different sites might again result in a wide variety of functional outcome [36].

This shows how crucial it is to summarize all the evidence obtained and to combine it, in order to confirm or to invalidate experimental results. We believe that metaanalytic approaches will allow increases in the level of evidence available, which is preferable to increasing the number of patients in a single study, which is barely achievable due to cost and time constraints. Possibly, the novel approach of comparing and contrasting results obtained in different, independent studies addressing the same research question under slightly different but related contexts will revolutionize biomarker discovery and validation, because this in silico research will result in the identification of common molecular features shared among different types of cancer histology - or allow molecular classification of these histological types. In a similar way, meta-analytic approaches will allow screening for translational patterns characterizing different clinical phenotypes, such as metastasis or therapy response.

\section{References}

$\checkmark 1$ Ferlay J, Autier P, Boniol M, Heanue M, Colombet M, Boyle P: Estimates of the cancer incidence and mortality in Europe in 2006. Ann Oncol 2007;18:581-592.

2 Travis WD, Brambilla E, Müller-Hermelink KK, Harris CC (eds): Pathology and Genetics of Tumours of the Lung, Thymus And Heart (World Health Organization Classification of Tumours). Lyon, IARC Press, 2004.

3 Rosai J: Surgical Pathology, ed 9. Edinburgh, Mosby, 2004

-4 Yang X, Sun X: Meta-analysis of several gene lists for distinct types of cancer: a simple way to reveal common prognostic markers. BMC Bioinformatics 20076;8:118.

5 Srour N, Reymond MA, Steinert R: Lost in translation? A systematic database of gene expression in breast cancer. Pathobiology 2008;75:112-118.

$\checkmark 6$ Chen JJ, Hsueh HM, Delongchamp RR, Lin CJ, Tsai CA: Reproducibility of microarray data: a further analysis of microarray quality control (MAQC) data. BMC Bioinformatics 2007;8:412.
7 http://www.ornl.gov/sci/techresources/Human_Genome/project/info.shtml(accessed September 15, 2008).

-8 Bernier G, Mathieu M, De Repentigny Y, Vidal SM, Kothary R: Cloning and characterization of mouse ACF7, a novel member of the dystonin subfamily of actin binding proteins. Genomics 1996;38:19-29.

-9 Taintor AR, Leiferman KM, Hashimoto T, Ishii N, Zone JJ, Hull CM: A novel case of IgA paraneoplastic pemphigus associated with chronic lymphocytic leukemia. J Am Acad Dermatol 2007;56(5 suppl):S73-S76.

10 Furukawa T, Sunamura M, Motoi F, Matsuno S, Horii A: Potential tumor suppressive pathway involving DUSP6/MKP-3 in pancreatic cancer. Am J Pathol 2003;162:18071815.

11 Sato M, Vaughan MB, Girard L, Peyton M, Lee W, Shames DS, Ramirez RD, Sunaga N, Gazdar AF, Shay JW, Minna JD: Multiple oncogenic changes (K-RAS(V12), p53 knockdown, mutant EGFRs, p16 bypass, telomerase) are not sufficient to confer a full malignant phenotype on human bronchial epithelial cells. Cancer Res 2006;66:21162128 .
12 Osada H, Tatematsu Y, Yatabe Y, Horio Y, Takahashi T: ASH1 gene is a specific therapeutic target for lung cancers with neuroendocrine features. Cancer Res 2005;65:10680 10685.

13 Lee JE, Raines RT: Ribonucleases as novel chemotherapeutics: the ranpirnase example. BioDrugs 2008;22:53-58.

14 Whiteman HJ, Weeks ME, Dowen SE, Barry S, Timms JF, Lemoine NR, Crnogorac-Jurcevic T: The role of S100P in the invasion of pancreatic cancer cells is mediated through cytoskeletal changes and regulation of cathepsin D. Cancer Res 2007;67:8633-8642.

15 Kargi A, Gurel D, Tuna B: The diagnostic value of TTF-1, CK 5/6, and p63 immunostaining in classification of lung carcinomas. Appl Immunohistochem Mol Morphol 2007; 15:415-420.

16 Paschoud S, Bongiovanni M, Pache JC, Citi S: Claudin-1 and claudin-5 expression patterns differentiate lung squamous cell carcinomas from adenocarcinomas. Mod Pathol 2007;20:947-954. 
-17 Tobioka H, Tokunaga Y, Isomura H, Kokai Y, Yamaguchi J, Sawada N: Expression of occludin, a tight-junction-associated protein, in human lung carcinomas. Virchows Arch 2004;445:472-476.

18 Katoh M: Trefoil factors and human gastric cancer. Int J Mol Med 2003;12:3-9. (Review.)

19 Mathelin C, Tomasetto C, Rio MC: Trefoil factor 1 (pS2/TFF1), a peptide with numerous functions.Bull Cancer 2005;92:773-781. (Article in French.)

20 Mossman BT, Lounsbury KM, Reddy SP: Oxidants and signaling by mitogen-activated protein kinases in lung epithelium. Am J Respir Cell Mol Biol 2006;34:666-699.

21 Romero P: Current state of vaccine therapies in non-small-cell lung cancer. Clin Lung Cancer 2008;9(suppl 1):S28-S36. (Review.)

-22 Ojika T, Imaizumi M, Abe T, Kato K: Immunochemical and immunohistochemical studies on three aldolase isozymes in human lung cancer. Cancer 1991;67:2153-2158.

-23 Dallüge KH, Eule H, Schulze G: Increase in serum aldolase caused by bronchial carcinoma. Arch Geschwulstforsch 1984;54:387390. (Article in German.)

-24 Stoffers M, Goldmann T, Branscheid D, Galle J, Vollmer E: Transcriptional activity of surfactant-apoproteins A1 and A2 in non small cell lung carcinomas and tumor-free lung tissues. Pneumologie 2004;58:395-399. (Article in German.)

25 Ota T, Maeda M, Suto S, Tatsuka M: LyGDI functions in cancer metastasis by anchoring Rho proteins to the cell membrane. Mol Carcinog 2004;39:206-220.

26 Pedersen N, Pedersen MW, Lan MS, Breslin MB, Poulsen HS: The insulinoma-associated 1: a novel promoter for targeted cancer gene therapy for small-cell lung cancer. Cancer Gene Ther 2006;13:375-384.

-27 Vieau D, Rojas-Miranda A, Verley JM, Lenne F, Bertagna X: The secretory granule peptides 7B2 and CCB are sensitive biochemical markers of neuro-endocrine bronchial tumours in man. Clin Endocrinol (Oxf) 1991; 35:319-325.

-28 Ceppi P, Volante M, Ferrero A, Righi L, Rapa I, Rosas R, Berruti A, Dogliotti L, Scagliotti GV, Papotti M: Thymidylate synthase expression in gastroenteropancreatic and pulmonary neuroendocrine tumors. Clin Cancer Res 2008;14:1059-1064.

29 Zheng Z, Li X, Schell MJ, Chen T, Boulware D, Robinson L, Sommers E, Bepler G: Thymidylate synthase in situ protein expression and survival in stage I nonsmall-cell lung cancer. Cancer 2008;112:2765-2773.
0 Rosti G, Carminati O, Monti M, Tamberi S, Marangolo M: Chemotherapy advances in small cell lung cancer. Ann Oncol 2006; 17(suppl 5):v99-v102. (Review.)

-31 Dalwadi H, Krysan K, Heuze-Vourc'h N, Dohadwala M, Elashoff D, Sharma S, Cacalano N, Lichtenstein A, Dubinett S: Cyclooxygenase-2-dependent activation of signal transducer and activator of transcription 3 by interleukin- 6 in non-small cell lung cancer. Clin Cancer Res 2005;11:7674-7682.

-32 Wu M, Wang B, Gil J, Sabo E, Miller L, Gan L, Burstein DE: p63 and TTF-1 immunostaining: a useful marker panel for distinguishing small cell carcinoma of lung from poorly differentiated squamous cell carcinoma of lung. Am J Clin Pathol 2003;119:696702 .

- 33 Fernandez-Sauze S, Delfino C, Mabrouk K, Dussert C, Chinot O, Martin PM, Grisoli F, Ouafik L, Boudouresque F: Effects of adrenomedullin on endothelial cells in the multistep process of angiogenesis: involvement of CRLR/RAMP2 and CRLR/RAMP3 receptors. Int J Cancer 2004;108:797-804.

34 Charalabopoulos K, Gogali A, Kostoula OK, Constantopoulos SH: Cadherin superfamily of adhesion molecules in primary lung cancer. Exp Oncol 2004;26:256-260. (Review.)

35 Fishel I, Kaufman A, Ruppin E: Meta-analysis of gene expression data: a predictor-based approach. Bioinformatics 2007;23:1599606.

36 Reymond MA, Schlegel W: Proteomics in cancer. Adv Clin Chem 2007;44:103-142. (Review.)

-37 Spira A, Beane JE, Shah V, Steiling K, Liu G, Schembri F, Gilman S, Dumas YM, Calner P, Sebastiani P, et al: Airway epithelial gene expression in the diagnostic evaluation of smokers with suspect lung cancer. Nat Med 2007;13:361-366.

38 Chen HY, Yu SL, Chen CH, Chang GC, Chen CY, Yuan A, Cheng CL, Wang CH, Terng HJ, Kao SF, Chan WK, Li HN, Liu CC, Singh S, Chen WJ, Chen JJ, Yang PC: A five-gene signature and clinical outcome in non-smallcell lung cancer. N Engl J Med 2007;356(1): 11-20.

39 Woenckhaus M, Klein-Hitpass L, Grepmeier U, Merk J, Pfeifer M, et al: Smoking and cancer-related gene expression in bronchial epithelium and non-small-cell lung cancers. J Pathol 2006;210:192-204.
40 Taniwaki M, Daigo Y, Ishikawa N, Takano A, Tsunoda T, Yasui W, Inai K, Kohno N, Nakamura Y: Gene expression profiles of smallcell lung cancers: molecular signatures of lung cancer. Int J Oncol 2006;29:567-75.

41 Bhattacharjee A, Richards WG, Staunton J, Li C, Monti S, Vasa P, Ladd C, Beheshti J, Bueno R, Gillette M, et al: Classification of human lung carcinomas by mRNA expression profiling reveals distinct adenocarcinoma subclasses. Proc Natl Acad Sci USA 2001;98:13790-13795.

42 Garber ME, Troyanskaya OG, Schluens K, Petersen S, Thaesler Z, Pacyna-Gengelbach $M$, van de Rijn M, Rosen GD, Perou CM, Whyte RI, Altman RB, Brown PO, Botstein $\mathrm{D}$, Petersen I: Diversity of gene expression in adenocarcinoma of the lung. Proc Natl Acad Sci USA 2001;98:13784-13789.

43 McDoniels-Silvers AL, Nimri CF, Stoner GD, Lubet RA, You M: Differential gene expression in human lung adenocarcinomas and squamous cell carcinomas. Clin Cancer Res 2002;8:1127-1138.

-44 Beer DG, Kardia SL, Huang CC, Giordano TJ, Levin AM, Misek DE, Lin L, Chen G, Gharib TG, Thomas DG, Lizyness ML, Kuick R, Hayasaka S, Taylor JM, Iannettoni $\mathrm{MD}$, Orringer MB, Hanash S: Gene-expression profiles predict survival of patients with lung adenocarcinoma. Nat Med 2002;8:816824.

-45 Amatschek S, Koenig U, Auer H, Steinlein P, Pacher M, Gruenfelder A, Dekan G, Vogl S, Kubista E, Heider KH, et al: Tissue-wide expression profiling using cDNA subtraction and microarrays to identify tumor-specific genes. Cancer Res 2004;64:844-856.

46 Wikman H, Seppanen JK, Sarhadi VK, Kettunen E, Salmenkivi K, Kuosma E, VainioSiukola K, Nagy B, Karjalainen A, Sioris T, Salo J, Hollmen J, Knuutila S, Anttila S: Caveolins as tumour markers in lung cancer detected by combined use of cDNA and tissue microarrays. J Pathol 2004;203:584-593.

47 Heighway J, Knapp T, Boyce L, Brennand S, Field JK, Betticher DC, Ratschiller D, Gugger M, Donovan M, Lasek A, Rickert P: Expression profiling of primary non-small cell lung cancer for target identification. Oncogene 2002;21:7749-7763.

48 Nakamura H, Saji H, Ogata A, et al: cDNA microarray analysis of gene expression in pathologic stage IA nonsmall cell lung carcinomas. Cancer 2003;97:2798-2805. 